\title{
Wagner disease
}

INSERM

\section{Source}

INSERM. (1999). Orphanet: an online rare disease and orphan drug data base. Wagner disease. ORPHA:898

Wagner disease is a rare hereditary vitreoretinopathy characterized by an anomaleous vitreous associated with myopia, cataract, chorioretinal atrophy, and peripheral tractional or rheg matogenous retinal detachment. 